\title{
BILATERAL RETINAL DETACHMENT FOLLOWING CAROTID-CAVERNOUS FISTULA*
}

\author{
BY \\ JOHN F. COGAN \\ St. Paul's Eye Hospital, Liverpool
}

CAVERnous sinus thrombosis can now be considered a rarity in this era of antibiotics, but sporadic cases still occur. However, the aetiology may be non-inflammatory, and Walsh (1937) gives the three commonest causes of thrombosis of the cavernous sinus as follows:

(1) Infective or inflammatory.

(2) Marasmic. This occurs in debilitating conditions at the extremities of life; the thrombus is always sterile.

(3) Traumatic. This may be due to a blow on the head or operative accident. The carotid artery ruptures within the cavernous sinus producing an arteriovenous communication or aneurysm, and sooner or later thrombosis occurs.

Cases of the third type are usually commoner in men, but Meadows (1951) has described nine cases of fistulous aneurysm arising spontaneously in middle-aged women. The sequence of events appears to be the development of an aneurysm of the internal carotid artery as it lies within the cavernous sinus bathed in venous blood. This aneurysm is small and silent, a large one being less likely to rupture as it is supported by the walls of the sinus. Meadows (1949) suggests that some cases may be due to local weakening of the arterial wall through arteriosclerosis without previous aneurysm formation.

After rupture an arterio-venous fistula develops with ensuing ophthalmic complications, notably lid oedema, chemosis, dilatation of the conjunctival vessels, and proptosis of the ipsilateral eye. A bruit heard over the eye or in some cases over the whole skull is characteristic. Later, the interval depending on the extent of the communications that exist between the two cavernous sinuses, similar signs appear on the opposite side. Other ocular complications include retinal haemorrhages and optic atrophy, the latter being due to pressure on the optic nerve by the enlarged cavernous sinus.

The final outcome depends on the size of the fistula. Dandy and Follis (1941) described a fistulous aneurysm in which the sac had ruptured in two places with a fatal result. In other cases a balance is obtained within the

* Received for publication April 8, 1959. 
arterio-venous shunt, and sometimes cure follows thrombosis of the cavernous sinus if this is sufficient to occlude the fistula. In that reported by Dandy and Follis (1941), a thrombus was found post mortem filling the inferior part of the sinus but was not extensive enough to reach either fistula.

\section{Case Report}

A single woman aged 53 years was admitted to hospital on July 17, 1957, with a history of pain and redness of the left eye associated with left-sided headache. There was no history of trauma. An $x$ ray of the sinuses had already been taken and was normal.

Examination.-She was a fairly well-built woman with normal temperature and pulse. The left eye was proptosed with lid oedema, chemosis, marked dilatation of the conjunctival vessels, and ophthalmoplegia. No clear view of the fundus was possible because of cloudiness of the vitreous, and the visual acuity was reduced to counting fingers.

The right eye appeared normal and the visual acuity was $6 / 9$.

A diagnosis of orbital cellulitis was made and systemic penicillin and Aureomycin were administered.

Treatment.-The next day the patient was transferred to the local Ear, Nose, and Throat Hospital. The systemic therapy was continued and she remained afebrile. A further $x$ ray of the sinuses was also clear.

Leucocyte Count : 10,000 per cu. mm., 75 per cent. neutrophils.

Urine: Nothing abnormal.

Progress.-On July 20 an early morning rise in temperature to $100^{\circ} \mathrm{F}$. was noted, but it then fell again to within normal limits. The chemosis and proptosis persisted.

On July 21 pain behind the right eye was complained of and the next day this eye was also proptosed with chemosis and dilatation of the conjunctival vessels. The temperature remained normal and a bruit could be heard over the forehead. There was however no complaint of a beating noise in the head. A further leucocyte count showed a total of 8,000 per cu. mm., 68 per cent. neutrophils.

The possibility of a carotid-cavernous fistula was considered and the patient was kept on antibiotics as a precaution. Her general condition remained quite good but she somewhat resented examination and wished to remain undisturbed. Chemosis and dilatation of the conjunctival vessels in both eyes persisted but there was no pulsation.

On August 8 she complained that the vision in both eyes was worse and fundal examination revealed bilateral retinal detachments involving the lower segments. No holes or tears were seen. The visual acuity was $6 / 60$ in the right eye and 4/60 in the left. Two days later the proptosis and chemosis of both eyes became much more pronounced, and was associated with considerable discomfort. For about 10 days this persisted with recurring attacks of pain. It must have been during this period that thrombosis of the cavernous sinus occurred. The bruit could no longer be heard.

On August 20 both retinal detachments were still present, the whole of the lower half of the right fundus showing considerable ballooning whilst the left detachment was limited to the temporal half of the lower segment. A week later chemosis and proptosis had subsided and both eyes appeared normal externally, but the detachments remained and in addition widespread pigmentation at the periphery of both fundi was noted.

She was transferred back to St. Paul's Eye Hospital and on October 10 the right detachment was tapped, a considerable quantity of subretinal fluid being evacuated. A week later the area of detachment was less but a small retinal haemorrhage was present at the site of the tapping. The visual acuity was $6 / 60$ in the right eye and 6/12 in the left.

On November 12 both detachments were still present, the retinal arteries somewhat attenuated, and pigmentary disturbances widespread. The patient had now been in 
hospital for 17 weeks and it was decided to allow her to go home although the detachments were still present.

After 2 weeks she returned as an outpatient, and to our surprise the detachments were flat. The visual acuity in the right eye was $6 / 18$, and in the left 6/12. The right visual field showed some loss above, but the left was practically full. After 4 months the vision was the same, the retinal arteries were still somewhat contracted, and pigmentary disturbances affected all quadrants, the maculae being spared.

At her last attendance 20 months after the onset of illness, the visual acuity in the right eye was 6/12, and in the left 6/9. No evidence of detachment was seen, but the defect in the right field had persisted. The patient had driven her own car from home to attend the clinic, a distance of $\mathbf{4 0}$ miles.

\section{Discussion}

A search through the literature has not revealed retinal detachment complicating defective drainage in the cavernous sinus in cases of carotidcavernous fistula or in thrombosis. Retinal detachments occurring in orbital cellulitis have been described on a few occasions (Duke-Elder, 1940, 1952; Malhotra, 1957), their presence being regarded as due to venous congestion and reactive oedema across the fibrous sclera. It seems unlikely that a similar aetiology existed in this case because, although there must have been considerable exudation which was passive in nature, the detachments were present long after the chemosis and dilatation of the conjunctival vessels had subsided.

Venous blood from the eye and orbit drains back into the cavernous sinus, but communications do exist with the pterygoid plexus. If this drainage is obstructed the well-known feature of bilateral proptosis, chemosis, and impaired mobility develops. The retinal veins are often dilated, but Parsons (1908) said that this was certainly not so in many cases and he explained the absence of such dilatation as being due to the free anastomoses of the ophthalmic veins and the posterior communications with the pterygoid plexus. Thus a large volume of blood from the central retinal vein may drain via these anastomoses. At the same time the amount of blood entering via the central retinal artery is decreased because of the raised intra-orbital pressure. Thus this smaller amount of blood will readily escape without producing dilatation of the retinal veins or swelling of the discs. At no time in the case described was dilatation of the retinal veins, retinal haemorrhage, or choked discs noted.

The detachments must have been exudative in nature; the source of the exudate was thought to be the choroidal circulation, the exudate being due to passive congestion, and the transudate passing into the subretinal space with resultant retinal detachment. Presumably the blood supply to the choroid is less affected in raised intra-orbital pressure than that to the retina, because of the greater number of "feeder" vessels. Thus, with a greater inflow, exudation occurs from the choroidal vessels. The widespread retinal 
pigmentary changes that occurred and have persisted are due to the diminished retinal circulation during the period of raised intra-orbital pressure.

The spontaneous re-attachments are explained as being due to some degree of re-cannulization of the thrombus in the cavernous sinus with full restoration of venous drainage from both eyes. The fact that both detachments re-attached spontaneously tends to bear this out.

The treatment is of course directed towards the arterio-venous fistula, carotid ligation not always being successful, the bruit returning later. If the course is non-progressive, treatment on expectant lines is probably the best. This was proved in this case where the resulting thrombosis of the cavernous sinus must have occluded the fistula. However the waiting period for spontaneous re-attachment must not be too long, and such a good return of vision as in the case here reported, where the detachments had lasted 17 weeks, is not always to be expected. Tapping may be tried, but such a procedure can be of a temporary nature only, for, if the obstruction to drainage remains, passive congestion will persist and further exudation into the subretinal space will occur. However, tapping may be used as a diagnostic measure, for examination of the fluid may show whether the disease process is inflammatory or passive in doubtful cases. The administration of retrobulbar cortisone to reduce capillary permeability is another possibility, but it was not tried in this case.

\section{Summary}

A case of bilateral exudative retinal detachment complicating a carotidcavernous fistula has been described. Cure followed aseptic thrombosis of the cavernous sinus, the detachments returning to position after an interval of 17 weeks, presumably because of partial re-cannulization of the thrombus.

I wish to thank Mrs. D. Barton and Mr. J. Siegler for permission to publish this case.

\section{REFERENCES}

DANDY, W. E., and Follis, R. H. (1941). Amer. J. Ophthal., 24, 365.

DUKE-ELDER, S. (1940). “Text-book of Ophthalmology", vol. 3, pp. 2610, 2611, 2650, 2872, 2873. Kimpton, London.

- (1952). Ibid., vol. 5, pp. 5428-5433.

Malhotra, M. (1957). Brit.J. Ophthal., 41, 317.

MeADOWs, S. P. (1949). Trans. ophthal. Soc. U.K., 69, 147. (1951). In "Modern Trends in Neurology", 1st ser., ed. A. Feiling, p. 425. Butterworth,
London.

Parsons, J. H. (1908). " "The Pathology of the Eye", vol. 4, p. 1227. Frowde, London.

WALSH, F. B. (1937). Arch. Ophthal. (Chicago), 17, 46. 